\title{
The specification of glycinergic neurons and the role of glycinergic transmission in development
}

\author{
Alexander V. Chalphin and Margaret S. Saha* \\ Department of Biology, College of William and Mary, Williamsburg, VA, USA
}

\section{Edited by:}

Robert J. Harvey, University of London, UK

\section{Reviewed by:}

Pascal Legendre, Universite Pierre et

Marie Curie, France

Hiromi Hirata, Nagoya University,

Japan

*Correspondence:

Margaret S. Saha, Department of Biology, Integrated Science Center, 540 Landrum Drive, College of William and Mary, Williamsburg, VA 23187,

USA.

e-mail:mssaha@wm.edu
Glycine's role as an inhibitory neurotransmitter in the adult vertebrate nervous system has been well characterized in a number of different model organisms. However, a full understanding of glycinergic transmission requires a knowledge of how glycinergic synapses emerge and the role of glycinergic signaling during development. Recent literature has provided a detailed picture of the developmental expression of many of the molecular components that comprise the glycinergic phenotype, namely the glycine transporters and the glycine receptor subunits; the transcriptional networks leading to the expression of this important neurotransmitter phenotype are also being elucidated. An equally important focus of research has revealed the critical role of glycinergic signaling in sculpting many different aspects of neural development. This review examines the current literature detailing the expression patterns of the components of the glycinergic phenotype in various vertebrate model organisms over the course of development and the molecular mechanisms governing the expression of the glycinergic phenotype. The review then surveys the recent work on the role of glycinergic signaling in the developing nervous system and concludes with an overview of areas for further research.

Keywords: glycine, glycinergic, review, neurotransmitter, development, embryo, phenotype

\section{INTRODUCTION}

In addition to its role in protein metabolism as the structurally simplest amino acid, glycine also serves as an important and widely distributed inhibitory neurotransmitter in the nervous system of animals from several phyla (Werman et al., 1968; Sawada et al., 1980, 1984; Mladinic et al., 1999 reviewed in Walker and Holden-Dye, 1991; Walker et al., 1996). While its role in adult neurotransmission is relatively well characterized, less is known about glycinergic signaling during development. Previous work has focused on examining the developmental expression of the glycine receptor and transporters as well as glycine immunoreactivity as a means of discerning the process whereby cells adopt a glycinergic phenotype. However several recent studies have begun to elucidate the mechanisms governing the development of the glycinergic phenotype as well as the role of glycine in neural development. For example, synaptic release of both glycine and GABA has been shown to play a determinative role in the proper development of many motor and sensory pathways, including those necessary for audition, vision, respiration, and nociception (Kirsch, 2006). Disruption of glycinergic transmission during neural development has also been shown to cause hyperekplexia, a disorder characterized by exaggerated startle responses, hypertonia and episodic neonatal apnea (Eulenburg et al., 2006; Rees et al., 2006). Differential expression of GlyR subunits over the course of development (namely $\alpha 2$ ) have been observed, although the function of such embryonic GlyRs have not yet been determined (Young-Pearse et al., 2006). Some evidence suggests that glycine has an early "pre" neuronal function, where taurine may act as an endogenous ligand in non-synaptic embryonic GlyR signaling to help coordinate the early neocortex, hippocampus and ventral tegmentum (Flint et al., 1998). More recently Scain et al. (2010) have described non-synaptic glycine signaling in the embryonic spinal cord.

A complete understanding of glycinergic transmission must entail knowledge of how cells acquire a glycinergic phenotype and the role of glycinergic signaling in development. This review summarizes the current understanding of glycinergic signaling in development. First, we examine the literature detailing the expression patterns of the molecular components of the glycinergic phenotype and glycinergic signaling in various vertebrate model organisms over the course of CNS development. Next we consider the molecular mechanisms governing the expression of glycinergic phenotype markers and the glycinergic phenotype. Finally, we review the current literature on the functional role of glycine signaling in the developing nervous system and then conclude with an overview of areas for further research.

\section{DEVELOPMENTAL EXPRESSION PATTERNS OF GLYCINERGIC PHENOTYPE MARKERS}

In vertebrates the biosynthesis of glycine for use in neurotransmission and general cellular metabolism is mediated by an enzyme differentially referred to as glycine synthase and glycine cleavage enzyme. This enzyme catalyzes a readily reversible reaction between carbon dioxide, ammonium ion, $\mathrm{N}^{5}, \mathrm{~N}^{10}$-methylene tetrahydrofolate, NADH and a proton to form glycine, tetrahydrofolate and $\mathrm{NAD}^{+}$. Immunohistochemistry and in situ hybridization experiments in rats have shown that the glycine cleavage system enzyme complex is expressed in embryonic neural stem/ progenitor cells, neuroepithelial cells, and astrocytes (Ichinohe et al., 2004). 
In addition to glycine itself, glycinergic transmission requires several additional molecular components. Two membrane-bound proteins, GlyT1 and GlyT2, members of the $\mathrm{Na}^{+} / \mathrm{Cl}^{-}$dependent neurotransmitter transporter family, serve to reuptake glycine from the synaptic cleft back into cells, with GlyT1 expressed predominantly by glial cells and GlyT2 serving as the primary neuronal glycine transporter. In addition, the vesicular inhibitory amino acid transporter (VIAAT), also commonly referred to as VGAT, transports both GABA and glycine into synaptic vesicles for later release into the synapse. Both GlyT2 and VIAAT must both be expressed for a cell to successfully perform as a glycinergic neuron.

The signaling function of glycine is mediated mainly by the glycine receptor (GlyR), a strychnine-sensitive member of the nicotinic acetylcholine receptor (nAChR) super family that is a ligandgated chloride anion channel (reviewed in Betz and Laube, 2006). GlyR is a pentameric protein with a stochiometry reported first as $2 \alpha / 3 \beta$ (Becker et al., 1988; Kuhse et al., 1993; Burzomato et al., 2003) and more recently as $3 \alpha / 2 \beta$ using a combined site directed mutagenesis and homology modeling approach (Grudzinska et al., $2005)$. Four $\alpha$ subunits $(\alpha 1, \alpha 2, \alpha 3$, and $\alpha 4)$ and one $\beta$ subunit have been characterized to date. The $\alpha 2$ and $\alpha 4$ subunits are expressed earlier in development compared to $\alpha 1$ and $\alpha 3$, which are generally only seen in the adult brain (Kuhse et al., 1991). Expression of $\alpha 2$ is observed before synaptogenesis, suggesting this subunit may play a role in pre-synaptic glycine signaling. Splice variants have also been observed for the $\alpha 1, \alpha 2$ and $\alpha 3$ subunits. The $\alpha 1$ splice variant $\left(\alpha 1^{\text {ins }}\right)$ includes eight additional amino acids and is expressed in the brainstem and spinal cord of mature rats (Kuhse et al., 1991; Malosio et al., 1991a). The $\alpha 2$ splice variants ( $\alpha 2 \mathrm{~A}$ and $\alpha \mathrm{B})$ differ by expression of two homologous exons and are both limited to expression in the early developing CNS (Grenningloh et al., $1990)$. Another $\alpha 2$ variant $\left(\alpha 2^{*}\right)$ is not generated through alternative splicing and has yet to be completely characterized (Kuhse et al., 1990). The $\alpha 3$ splice variant $\alpha 3 \mathrm{~L}$ has a very similar primary structure to $\alpha 3$ while the splice variant $\alpha 3 \mathrm{~K}$ lacks a 15 amino acid sequence. Both $\alpha 3$ splice variants are observed in the human fetal brain (Nikolic et al., 1998; reviewed in Legendre, 2001). While the exact role of the $\alpha$ and $\beta$ subunits in agonist binding is unclear (Grudzinska et al., 2005), binding between the large cytoplasmic loop of the $\beta$ subunit and the anchoring protein gephyrin has been well characterized (Kneussel et al., 1999). Gephyrin binding has been implicated in synaptogenesis, but uncertainty still remains over the necessity of gephyrin for synapse formation (Feng et al., 1998; Meier et al., 2000; Levi et al., 2004). In order to understand the process by which cells adopt a glycinergic phenotype, investigators have conducted numerous studies examining the ontogeny and developmental expression patterns of each of these molecular components in a variety of different species.

\section{GLYCINE}

The presence of glycine immunoreactivity (IR) in neuronal and glial cells has served as the primary marker for the development of the glycinergic phenotype and has been the subject of developmental expression studies in a number of different organisms, particularly in mammals. In mice, Allain et al. (2006) observed little IR before embryonic day 12.5 (E12.5) in the mouse spinal cord, at which time glycine IR was visualized in the somata of ventral horn cells and in fibers at the edges of the marginal zone. One day later glycine IR begins to appear in the dorsal horn, intensify in cells in the ventral horn, and decrease in the marginal zone. By E16.5 IR reaches near adult levels in both the ventral and dorsal horns. These investigators also observed the colocalization of GABA and glycine IR in a third of all glycine positive cells, with the glycinergic system maturing a day after the GABA system (Allain et al., 2006; Sibilla and Ballerini, 2008).

Glycine IR in the mammalian retina has also been extensively studied. Immunostaining for glycine of the rat retina revealed the presence of the neurotransmitter in cells of the ventricular zone and the retinal pigmented epithelium (RPE) from birth. These cells extended processes to the neuroblastic layer of the outer retinal edge, indicating that they may be developing bipolar or amacrine cells. IR positive cells were seen migrating through the ventricular zone by day postnatal day 4 (P4), when subpopulations of glycine positive amacrine cells were first observed in the inner plexiform layer (IPL). Over the next 2 days the amacrine cells of the IPL became less diffuse at the IPL borders and expression decreases in the RPE. Near adult expression is finally achieved by P11 (Fletcher and Kalloniatis, 1997).

Glycine IR has also been examined in chick embryos with positive staining first observed on E8 in the dorsal and ventral grey matter of chick embryos. The number of positive cells rises sharply 2 days later and reaches near adult expression by day 12 . The majority of the IR positive neurons were observed in the dorsal horn lamina IV, V and VI. Glycine positive cells were also observed in the lamina VII and diffusely distributed throughout the spinal grey matter. In chick embryos, similar to mammals, GABA appears 4 days earlier than glycine, and is observed in the ventral horn and does not share the same distribution as glycine IR cells in the spinal grey matter (Berki et al., 1995).

Amphibian embryos have served as a classic model system for examining the development of the glycinergic phenotype (Roberts et al., 1988). In Xenopus laevis the first glycine positive IR cells appear in the rostal spinal cord and caudal hindbrain intermediate between ventral and dorsal at stage 22, a few hours after the neural tube closes. Glycine expression extends caudally while the more rostral regions in-fill as the embryo matures. At stage 25 only unipolar glycine IR cells were observed, but axons and growth cones can be easily visualized by stage 27 . Neuron numbers can be accurately quantified up to stage 27, after which time the concentration of glycine positive cells can exceed 30 per $100 \mu \mathrm{m}$. By stage 37 (swimming tadpole stages), glycine IR in the spinal cord is mostly dorsal, with clear axons descending ventrally (Roberts et al., 1988).

Because of its unique phylogenetic position as a jawless fish, lamprey has been the focus of comparative expression studies for neurotransmitter markers including glycine. Glycine IR was first observed in the caudal rhombencephalon at E5, followed by the diencephalon of early prolarvae and then the mesencephalon by P15. Within these areas, glycine immunostaining occurred in CSF-c cells of the preoptic nucleus and postoptic-buberal cell group, post-optic commissural region, ventral and dorsal thalamus, pretectum, and M5 nucleus of Schober. IR was seen in the isthmic, trigeminal, and octaval levels of the ventrolateral neuropil and the vagal region of the caudal rhombencephalon. At this late prolarval stage, glycine was observed in the proptic nucleus, hypothalamus, 
thalamus, pretectum and the nucleus of the medial longitudinal fascicle, mesencephalon, isthmus and rhombencephalon. Later in the true larvae stage, glycine IR was found in olfactory bulb, preoptic nucleus, oculomotor nucleus, dorsal isthmic gray and isthmic reticular formation. GABA and glycine appear to co-localize in the M5 nucleus, reticular formation, and dorsal column nucleus during larval stages (Villar-Cervino et al., 2009). In the lamprey retina, glycine IR is first seen in the inner plexiform layer during early metamorphosis stages (M1). Near-adult expression, including IR in the inner and outer plexiform layers, inner and outer nuclear layers and the horizontal cell layer, is seen by late transformation stages (M6) (Abalo et al., 2008). Many taxa and areas of the CNS remain to be assayed for glycine IR, making comparing expression patterns between organisms difficult. The data currently available in mice, chick and frogs suggests that glycine first appears in the spinal cord after GABA across all three taxa. In the retina, on the other hand, differences in the life cycles of mice and lamprey, the two species assayed for glycine IR in the retina, prevents much comparison. The lamprey undergoes a maturation process where they can remain functionally blind larvae for up to 8 years before adulthood (Villar-Cervino et al., 2009).

\section{GLYCINE TRANSPORTERS}

Given the somewhat problematic nature of distinguishing between the amino acid glycine present in all cells and the low levels of neurotransmitter-specific glycine at early stages of development using immunohistochemistry, detection of glycine transporter expression at the mRNA and/or protein level has served as a valuable tool for analyzing the development of the glycinergic phenotype. GlyT1 and GlyT2 immunostaining are observed earliest in the mouse and rat at E10 in the midbrain floor plate and E12, respectively. By E17 two areas of GlyT1 expression are visible at the borders between the thalamus and hypothalamus and the border between the dorsal thalamus and zona incerta. GlyT2 levels rise in the ventral white matter of the spinal cord at E14 and then in the dorsal funiculus, reticular formation, spinal trigeminal nucleus, thalamus, cerebellum, colliculi and central tegmental tract at E17 (Jursky and Nelson, 1996). A study focusing on the auditory system observed GlyT2 IR develop from no staining at E18 to positive staining in all brainstem nuclei by $\mathrm{P} 4$. Next perisomatic and increased punctate signal developed in all brainstem nuclei except the inferior colliculus and medial geniculate body. Immunostaining decreased across the auditory system after P10 and adult expression levels were achieved within 4 weeks of birth (Friauf et al., 1999). In the rat spinal cord GlyT1 is first observed at E11 in the ventral ventricular zone. Immunostaining for VIAAT (VGAT) in the mouse retina confirms that glycinergic neurons appear in a similar pattern to the rat retina. IR occurs in the inner retina by $\mathrm{P} 1$, the outer retina by $\mathrm{P} 3$ and $\mathrm{P} 5$ in mouse and rat respectively, and adult expression in both by P11 (Johnson et al., 2003).

In lower vertebrates glycine transporters have generally been analyzed at the mRNA rather than the protein level. Higashijima et al. (2004) first observed glycinergic neurons in the zebrafish Danio rerio via in situ hybridization against GlyT2 in the mediodorsal domain of the rostral spinal cord 20-h post-fertilization (hpf). These results are consistent with the first appearance of rhythmic firing in interneurons of the dorsal spinal cord believed to be caused by glycinergic neurons. Brain expression was not observed until 3-day postfertilization (dpf), where a stark line is observed in the rostral hindbrain near rhombomeres 1 and 2. Some very weak expression is also seen in the ventral midbrain at this stage. Near complete expression was observed by this group by four dpf.

The other glycine transporter, GlyT1, is expressed in the hindbrain and spinal cord of the developing zebrafish in a non-overlapping pattern. In Situ hybridization using GlyT1 specific probe reveals that the transporter is expressed in the rostral spinal cord by at least $18 \mathrm{hpf}$. By $24 \mathrm{hpf}$ GlyT1 expression is observed in five dorsal stripes in the hindbrain and along the dorsal midline of the caudal hindbrain and spinal cord. By the next day ( $48 \mathrm{hpf}$ ) the transporter is observed along the dorsal midline of the midbrain, hindbrain and spinal cord and the floor plate cells of the hindbrain and spinal cord. At $72 \mathrm{hpf}$ hindbrain expression spreads but remains mostly dorsal and superficial. The strongest signal in the hindbrain at this point is along the ventricle border. The medial, floor plate, and dorsal midline cells of the spinal cord also begin to express GlyT1 at this point (Cui et al., 2005).

Expression studies in Xenopus laevis have revealed the appearance of GlyT1 first in the proliferative ventricular zone and intermediate zone of the midbrain, the ventricular layer of the hind brain, and the intermediate region of the anterior spinal cord during early tailbud stages (stage 24). By the time the tadpole can swim GlyT1 appears in the forebrain, retina, somites and blood islands. GlyT2 and VIAAT are initially expressed earlier than Gly $\mathrm{T} 1$ in the anterior spinal cord of the late neurula (stage 21). By stage $33 \mathrm{GlyT} 2$ is found in the lateral forebrain, medial midbrain and mid-dorsal region of the spinal cord. VIAAT is expressed more widely slightly earlier (stage 27). Expression for the vesicular transporter is observed in the ventral and lateral regions of the telencephalon, the dorsal, ventral, and midpoint of the dorsal-ventral axis in the diencephalon and the intermediate zone of the spinal cord. VIAAT mRNA was also detected in ventral Kolmer-Agduhr cells of the spinal cord (Wester et al., 2008). Other investigators have shown that GlyT1 and GlyT2 are expressed in the ganglion and inner nuclear layers of the frog (Rana pipiens) and rat retinas (Pena-Rangel et al., 2008).

\section{GLYCINE RECEPTOR}

While no systematic analysis of all four GlyR $\alpha$ subunits and the $\beta$ subunit has been conducted, there are several reports using immunohistochemistry and in situ hybridization for various subunits in some model species. Early immunostaining for GlyR in the rat supports glycinergic expression elucidated through glycine IR. The $\alpha 1$ subunit is first seen in the rat spinal cord at E14, after which time mRNA signal steadily increases in the ventral and dorsal horns until leveling off at P15. In the brain $\alpha 1$ is detected at near adult by P5. At E15 the $\alpha 2$ subunit is expressed in the telencephalon, diencephalon, midbrain and the first layer of the cortex, and remains through early postnatal stages (P5). Layers I, II and IV are all strongly labeled by $\mathrm{P} 5$, and adult expression is achieved by P15 with the addition of staining to layer VI. The remaining GlyR subunit, $\alpha 3$, is not observed until relatively late in development (P5), but remains throughout life. Initially the colliculi of the reticular thalamic nucleus are significantly stained, followed much later by the cerebellum at P40. The $\alpha 3$ subunit is not heavily expressed in the spinal cord, but is seen in both ventral and dorsal horns between E19 and P20. The $\beta$ 
subunit of GlyR is first expressed at E14 in both the telencephalon of the brain and the ventral and dorsal horns of the spinal cord. Although adult expression is accomplished quickly after E14 in the spinal cord, brain expression of the $\beta$ subunit is more dynamic. At E19 the first two layers of the cortex, septum, Ammon's horn of the hippocampal formation, thalamus and midbrain are stained. Adult expression, now including the VI layer of the cortex, entorhinal cortex, hippocampus and subiculum occurs by P15 (Malosio et al., 1991b). The postnatal rat retina shows GlyR expression in the neuroblastic layer, while GlyR in the adult is only observed in the inner nuclear layer (INL) (Sassoe-Pognetto and Wassle, 1997). Young and Cepko (2004) have also shown that GlyR and specifically GlyR $\alpha 2$ are expressed in retinal progenitor cells at birth. GlyR is differentially expressed in OFF cone bipolar cells, but not ON cone bipolar cells. GlyR with $\alpha 1$ subunits was observed uniformly on the dendrites of parasol and midget ganglion cells in the same study (Grunert, 2000).

In the developing chick retina immunoreactivity against GlyR does not appear in the IPL until E12. The adult GlyR subunit $\alpha 1$ is not observed until E16 when it is seen punctate at synapses, suggesting that subunit expression is variable over the course of development (Hering and Kröger, 1996).

Immunohistochemistry against GlyR $\alpha 2$ and GlyR $\alpha 3$ shows distinct expression in the adult Xenopus laevis retina, while GlyR $\alpha 1$ immunostaining shows no expression. GlyR $\alpha 2$ expression is observed mostly in the IPL, consisting of a thin, horizontal distal band and a broader, proximal horizontal band. Some scattered puncta are also observed in the INL. Similar patterns are seen with GlyR $\alpha 3$ immunostaining in the IPL, although scattered puncta are also detected in the OPL (Vitanova, 2006).

Although no detailed immunohistochemistry or in situ hybridization studies have been conducted for GlyR $\beta$ in Zebrafish, Hirata et al. (2005) did perform a series of RT-PCR assays for GlyR $\beta 1$ and GlyR $\beta 2$ over the course of embryonic CNS development. They found that GlyR $\beta 1$ is first expressed by the end of the first day of development, while GlyR $\beta 2$ is expressed first at day 3. GlyR $\beta 1$ is expressed in repeating bilateral clusters of cells in the hindbrain extensively expressed in the spinal cord at the end of the first day, with expression increasing and expanding through the second day (Hirata et al., 2005). In situ hybridization for GlyR $\alpha 2$ mRNA revealed expression at day one, but no expression at day two in optical sections of the spinal cord. GlyR $\alpha 1$ is also expressed in the spinal cord during the first day of embryonic development, but then increases in intensity in the spinal cord by day two (McDearmid et al., 2006). mRNA for the GlyR $\alpha 2$ subunit was observed in the outer nuclear layer of the adult zebrafish retina, but studies have not been conducted for these mRNAs more widely throughout the developing organism (Imboden et al., 2001).

\section{COLOCALIZATION AND COMPARATIVE EXPRESSION PATTERNS}

The co-localization and comparative expression kinetics of glycine and GABA present an under examined dimension of glycine's role in development. In general, the expression of glycinergic markers mirrors that of GABAergic markers. GABA tends to appear earlier and reach mature expression earlier than glycine, while glycine occasionally replaces GABA as the predominant inhibitory neurotransmitter (Allain et al., 2006). Immunostaining in the rat brain for GABA and glycine, for example, revealed a stark transition from GABA to glycine neurotransmission in the lateral superior olive. Co-expression of both GABAergic and glycinergic markers also change during development. In the mouse hypoglossal nucleus, for instance, $30 \%$ of GlyR positive cells are also IR for $\gamma 2 \mathrm{GABA}_{\mathrm{A}} \mathrm{R}$ at E17, a statistic that increases to $50 \%$ by P30 (Muller et al., 2004). The opposite transition appears in the lamprey, presenting one of the most significant differences in expression yet observed among chordates (Villar-Cervino et al., 2009). Both glycinergic and glutamatergic neurons are associated with rhythmic firing patterns, and as expected are both observed in the same areas of the developing zebrafish spinal cord, albeit not lo-localized on the cellular level. Before $30 \mathrm{hpf}$ GlyT2 and the GABAergic marker glutamic acid decarboxylase (GAD) are colocalized in the majority of IR positive neurons for either marker. After $30 \mathrm{hpf}$ most neurons become either glycinergic or GABAergic (Higashijima et al., 2004). Glutamate appears to be dominant in immature P6 amacrine cells, while glycine IR is observed in most adult amacrine cells (Fletcher and Kalloniatis, 1997). In the rat spinal cord synaptic co-localization of GlyR and GABA receptors occur at numerous layers. Gao et al. (2001) suggest that this redundant expression, combined with the observation that these amino acids are stored in the same synaptic vesicles, indicates a synergistic function of the two neurotransmitters that could help fine tune synaptic integration. In the rat retina, GABA and glycine immunostaining reveals co-localization in a minority of amacrine cells (Fletcher and Kalloniatis, 1997). Todd et al. (1996) take the question of co-localization a step further and examined the relationship between presynaptic glycine and GABA, and postsynaptic GlyR and GABA receptors in the rat spinal cord. This group reports that the observed co-IR for presynaptic glycine and GABA and postsynaptic gephyrin (as a marker for GlyR) and GABA receptors supports GABA and glycine cotransmission. Studies on GABA receptors alone, however, reveal no relationship between presynaptic input and aggregation of GABA receptors in rat hippocampal cells or cerebellar granule cells (Nusser et al., 1996, 1998; Kannenberg et al., 1999; Rao et al., 2000).

Taken together, these numerous studies of the expression patterns of glycinergic neurons in the developing vertebrate nervous system demonstrate similar emergence across lineages (see Table 1). Glycinergic neurons tend to appear during embryonic development in the rostral spinal cord, followed by increased expression caudally down the spinal cord and rostrally into the hindbrain, midbrain and retina. Although there are indications of differential regulatory mechanisms even between closely related species (Jursky and Nelson, 1996), this general pattern is maintained. These observations suggest that, despite small changes in the mechanisms organizing the distribution of glycinergic neurons, these neurons likely perform similar functions during the formation of later neural networks.

\section{GLYCINE IN INVERTEBRATES}

It was long believed that glycinergic neurotransmission was an almost purely vertebrate phenomenon. Walker et al. (1996) reported that no evidence has been found for glycinergic transmission in the nematodes, arthropods or annelids. Until relatively recently it was thought that the cnidarians lacked the ability to use 
Table 1 | Summary of embryonic and early postnatal expression patterns for glycinergic markers.

\begin{tabular}{|c|c|c|c|c|c|c|}
\hline Region & Lamprey & Zebrafish & Frog & Chick & Mouse & Rat \\
\hline Brain & $\begin{array}{l}\text { GlycinelR: caudal } \\
\text { rhombencephalon } \\
\text { E5; prosencephalon } \\
\text { P2; diencephalon } \\
\text { and } \\
\text { mesencephalon, } \\
\text { P15; widespread in } \\
\text { true larval through } \\
\text { adult stages. }\end{array}$ & $\begin{array}{l}\text { GlyT2: } \\
\text { mRNA } \\
\text { rostral HB } \\
\text { and ventral } \\
\text { MB 3DPF }\end{array}$ & $\begin{array}{l}\text { GlyT1: mRNA } \\
\text { MB+HB/HB St. 24; } \\
\text { FB+MB+HB St.27 } \\
\text { GlyT2: mRNA } \\
\text { MB+HB/HB St.31; } \\
\text { FB+MB+HB low } \\
\text { levels St. } 33 \\
\text { VIAAT: mRNA } \\
\text { MB+HB/HB St. 24; } \\
\text { FB+MB+HB St.27 }\end{array}$ & N/A & $\begin{array}{l}\text { GlyT1: IR midbrain } \\
\text { floor plate E10; } \\
\text { borders of } \\
\text { thalamus/MB+HB } \\
\text { E17; adult levels } \\
\text { after P5 } \\
\text { GlyT2: IR borders } \\
\text { of thalamus/ } \\
\text { MB+HB E17; all } \\
\text { brainstem nuclei } \\
\text { by P4; adult levels } \\
\text { after P5 }\end{array}$ & $\begin{array}{l}\text { GlyR } \alpha \mathbf{1} \text { : mRNA near adult } \\
\text { by P5 } \\
\text { GlyR } \alpha \mathbf{2} \text { : mRNA } \\
\text { telencephalon, } \\
\text { diencephalon, MB, cortex } \\
\text { P5 } \\
\text { GlyR } \alpha 3 \text { : mRNA colliculi of } \\
\text { RTN P5, cerebellum P40 } \\
\text { GlyR } \beta \text { : mRNA FB, MB E19 }\end{array}$ \\
\hline Retina & $\begin{array}{l}\text { Glycine IR: IPL, } \\
\text { M1; ONL, OPL, } \\
\text { HCL, INL, IPL, M6 }\end{array}$ & $\begin{array}{l}\text { GlyR } \alpha \mathbf{1} \\
\text { mRNA ONL } \\
\text { of adult }\end{array}$ & $\begin{array}{l}\text { VIAAT: mRNA INL } \\
\text { St.27 } \\
\text { GlyT1: mRNA INL, } \\
\text { ONL } \\
\text { GlyT2: mRNA INL, } \\
\text { ONL }\end{array}$ & $\begin{array}{l}\text { GlyR: IR IPL } \\
\text { E12 }\end{array}$ & $\begin{array}{l}\text { VIAAT: IR inner } \\
\text { retina P1; outer } \\
\text { retina P3; adult by } \\
\text { P7 }\end{array}$ & $\begin{array}{l}\text { Glycine IR: ventricular zone } \\
\text { and RPE/RPC P0; } \\
\text { neuroblastic layer P4; } \\
\text { amacrine cells P6; adult } \\
\text { levels P11 } \\
\text { GlyT1: mRNA INL, ONL } \\
\text { adult } \\
\text { GlyT2: mRNA INL, ONL } \\
\text { adult } \\
\text { VIAAT: IR inner retina P1; } \\
\text { outer retina P5; adult by P7 } \\
\text { GlyR } \alpha \mathbf{1} \text { : IR ganglion cells } \\
\text { adult } \\
\text { GlyR } 2 \text { 2: mRNA ventricular } \\
\text { zone + RPE/RPC + IR } \\
\text { neuroblastic layer P0; only } \\
\text { INL in adult }\end{array}$ \\
\hline
\end{tabular}

Summary of embryonic and adult expression patterns of glycinergic markers.

SC, spinal cord; HB, hind brain; IR, immunoreactivity; RPE, retina pigment epithelium; ONL, outer nuclear layer; OPL, outer plexiform layer; HCL, horizontal cell layer; INL, inner nuclear layer; IPL, inner plexiform layer; RTN, reticular thalamic nucleus; $M$, metamorphosis stage; HPF, hours postfertilization; DPF, days postfertilization; P, postnatal; E, embryonic.

glycine as a neurotransmitter (Grimmelikhuijzen et al., 2002). It is now suspected that many phyla from the simple hydra to our own primate lineage use similar classical neurotransmitters (including glycine) that first evolved 1000 million years ago (reviewed in Walker and Holden-Dye, 1991; Walker et al., 1996). Some notable exceptions include nematodes and insects, neither of which have functional glycine receptors and instead use GABA or glutamate to mediate inhibitory neurotransmission (Ui-Tei et al., 1995; Bargmann, 1998). Although evidence for functional GlyRs in these groups has yet to appear, Drosophila appear to possess 25-30 genes for GABA/glycine receptors and C. elegans appear to possess 10 receptor genes (Yoshihara et al., 2001). In 2001 the first cnidarian glycine receptors were identified and characterized via biochemical and behavioral studies in Hydra vulgaris. These receptors were found to mirror the function of vertebrate glycine receptors; they are sensitive to both glycine and taurine, which can displace previously bound strychnine (Pierobon et al., 2001). Tino et al. (2005) began the process of cloning and expressing H. vulgaris glycine receptors. Glycine also appears to play a role in the coelenterate pacemaker system, where 
it functions to inhibit endodermal pacemakers through glycine receptor binding and excite the pacemakers through NMDA receptor interactions (Ruggieri et al., 2004). In the adult glycinergic neurotransmission has been implicated in mouth opening during feeding (Pierobon et al., 2001, 2004). Kehoe et al. (2009) used sequence data from Aplysia 2-cys-loop gated chloride ion channels from Aplysia, a member of the platyhelminthes lineage to suggest that glycinergic neurotransmission may occur in this group. Glycinergic neurotransmission among invertebrates overall is poorly understood, and many more phyla must be examined before a complete picture of the evolution of this neurotransmitter can be developed.

\section{DETERMINATION OF THE GLYCINERGIC PHENOTYPE}

While expression pattern data has provided essential information on when the glycincergic phenotype emerges during embryonic development, the molecular mechanisms governing the process remain poorly understood. The glycinergic neurotransmitter phenotype requires the expression of the transporters GlyT2 and VIAAT for proper neurotransmission (reviewed in Betz and Laube, 2006). In part this is attributable to the fact that the glycinergic phenotype is so closely associated with the GABAergic phenotype. Both types of neurons use the same vesicular transporter VIAAT to mediate accumulation of the neurotransmitter into synaptic vesicles. GlyT2, however, plays an important role in switching between specific neurotransmitter phenotypes. In fact, Aubrey et al. (2007) observed increased release of glycine in neuroendocrine serotonergic BON cells made to express one of the two glycine transporters in a series of experiments using a novel double sniffer patch clamp technique. The neural glycine transporter GlyT2 also appeared to be more efficient than the glial glycine transporter GlyT1. By using Caenorhabditis elegans, a species which does not use glycinergic neurotransmission, these investigators were able to show that increasing cytosolic glycine plays an important role in switching neurotransmitter specification.

The specificity of the GlyT2 for the neuronal glycinergic phenotype provides another approach for analyzing the molecular mechanisms mediating the specification of this neurotransmitter phenotype, namely "working backwards" employing a reverse genetic approach through analysis of the upstream regulatory regions of the gene. The regulatory mechanisms of these terminal differentiation genes have been partially elucidated in some model species. Most of the work on the transcriptional regulation of GlyT2 has been conducted in the mouse and rat (Adams et al., 1995; Ponce et al., 1998; Ebihara et al., 2004). Ponce et al. (1998) report three GlyT2 transcriptional isoforms in the rat and Ebihara et al. (2004) report three other GlyT2 transcriptional isoforms in the mouse, each driven by an alternative promoter. GlyT2a is five amino acids shorter than the GlyT2b isoform at the N-terminal, and is able to accumulate glycine in COS. The GlyT2b isoform appears to only be able to exchange glycine. Zeilhofer et al. (2005) have developed transgenic mice with EGFP expression glycinergic neurons by using a $\mathrm{BAC}$ vector with $105 \mathrm{~kb}$ of 5 ' flanking DNA and $21 \mathrm{~kb}$ of 3 ' flanking DNA from the GlyT2 gene. To date no detailed functional studies of the GlyT2 promoter have been conducted in any model organism.
Another promising approach for unraveling the mechanism of glycinergic specification has been an analysis of various transcription factors whose expression correlates with that of GlyT2, in particular Ptfla, Lbx1 and Pax2 (Figure 1). Investigations of Ptfla, Lbx1, and Pax 2 by Huang et al. (2008) were used to generate a model of the relationship between these three transcription factors in the dorsal spinal cord. Experiments on null mice embryos for combinations of these factors show that all three factors are necessary for expression of the glycinergic phenotype. Developing dorsal horn neurons in Ptf1a null embryos fail to express GlyT2 from E12.5 through E16.5 and Pax2 $2^{-/-}$mice also fail to express GlyT2 properly from E12.5 through E18.5. GlyT2 production was observed, albeit at reduced intensity in Lbx1 homozygous negative mice. While these transcription factors clearly play a powerful role in the developing dorsal horn they did not appear necessary in the ventral horn. Overexpression experiments of these transcription factors also resulted in the development of ectopic inhibitory neurons producing either glycine or GABA. These studies also showed that Lbx 1 alone is able to induce switching from GABAergic to glycinergic specifications. According to these authors Ptfla appears to act as a master regulator of developing inhibitory neurons of the dorsal spinal cord, and can act in conjunction with Lbx1 to activate Pax2 as a downstream target. Pax2, in turn, has been shown to activate transcription of GlyT2 and other differentiation targets. Ptfla has also been shown to play a role in the development of GABAergic and glycinergic cells in other areas of the CNS, including horizontal and amacrine cells of the mouse retina and glycinergic neurons of the cochlear nucleus. Recombination-based lineage tracing suggests that the transcription factor is expressed in precursors of both retinal cell types. Inactivation of Ptf1 a prevents differentiation of horizontal and amacrine cells during retina development (Nakhai et al., 2007). Ptf1a null mouse embryos fail to develop inhibitory GABAergic and glycinergic neurons and Atoh1 null embryos fail to develop excitatory glutamatergic neurons in the cochlear nucleus(Fujiyama et al., 2009).

Batista and Lewis (2008) have also examined the role of Pax2, including both of its isoforms (Pax2a and Pax2b) and Pax8 in glycinergic differentiation. They showed that expression of each of any of these three transcription factors leads most often to adoption of the glycinergic phenotype. Morpholino knockdown of these transcription factors supported the redundant role of Pax $2 \mathrm{a} / \mathrm{b}$ and Pax8, as the glycinergic specification is not lost unless all three transcription factors are knocked down. Lhx1 and Lhx 5 are expressed in inhibitory interneurons of the dorsal spinal cord and have been shown to increase expression of Pax2. Knockdown of Lhx1 and Lhx5 results in decreased expression of VIAAT, although they do not appear to be obligatory determinant of inhibitory neural phenotypes and appear to play no direct role in determining GlyT2 expression (Pillai et al., 2007). Neuron restrictive silencing factor has been shown to act as a repressor of the GlyR $\alpha 1$ subunit through binding to the 5' region of the GlyR $\alpha 1$ mRNA in studies of smallcell lung cancer cell-derived cell lines (Gurrola-Diaz et al., 2003; Neumann et al., 2004).

Specification of glycinergic amacrine in the retina appears to involve the homeobox gene Barhl2. Immunostaining of the developing retina for the transcription factor by Mo et al. (2004) revealed positive IR in both postmitotic amacrine and ganglion cells. Forced 


\section{Transcription Factors Involved in Glycinergic Specification}

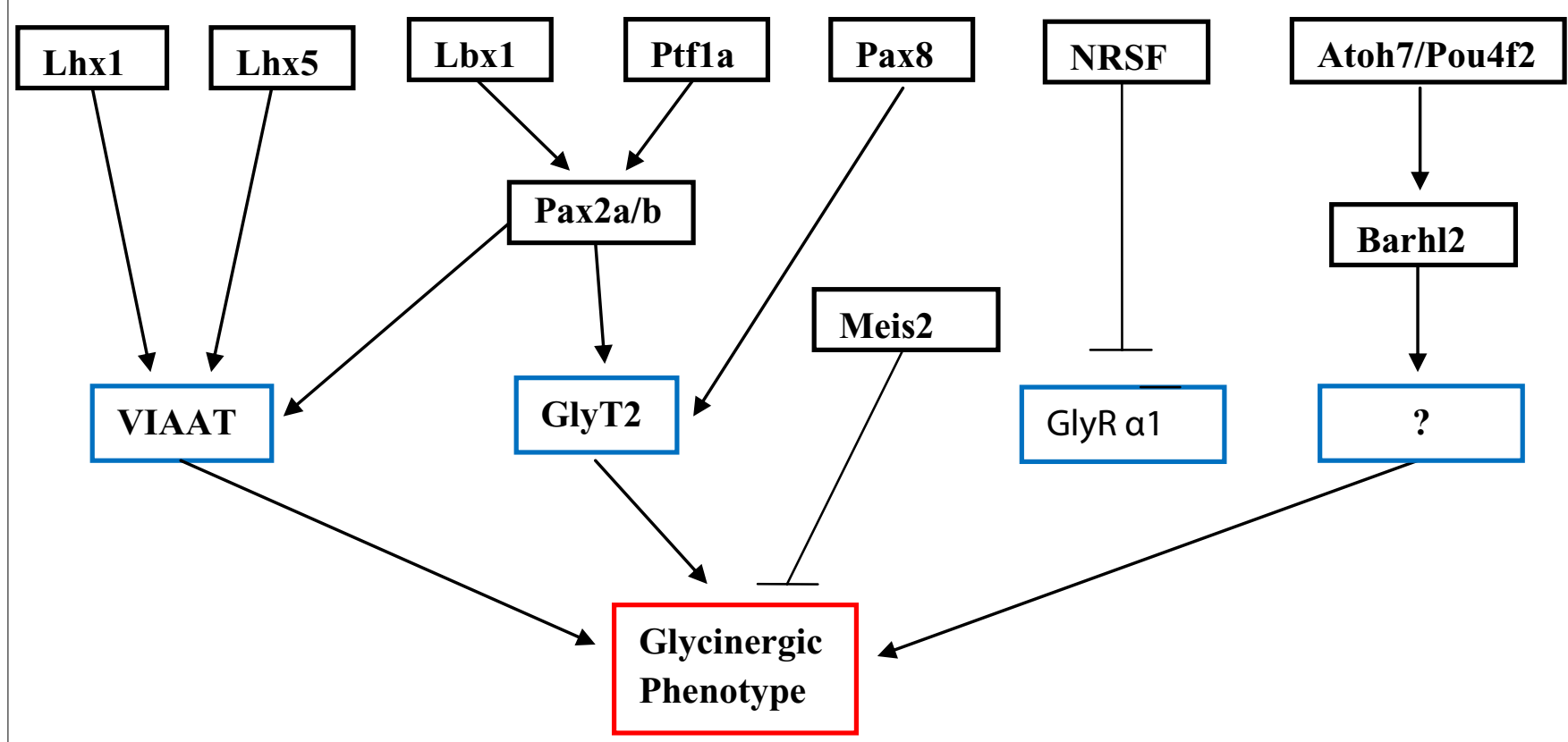

FIGURE 1 |A model for the roles of transcription factors Ptf1a, Lbx1, Pax2a/ b, Pax8, Lhx1, Lhx5 and NRSF in regulating terminal differentiation genes of glycinergic neurons based upon current literature cited in text. $L b \times 1$ and Ptf1a act together to control Pax2-dependent expression of VIAAT and GlyT2.
Pax8 acts redundantly with Pax2 on GlyT2, while $L h \times 1$ and $L h \times 5$ also up-regulate VIAAT. NRSF down regulates the $\alpha 1$ subunit of GlyR and does not appear to act on either GlyT2 or VIAAT. Atoh7 and Pou4f2 both act upstream of Barhl2. The exact mechanism of this interaction is unknown, as is the target of Barhl2. expression of Barhl 2 resulted in more frequent differentiation of retinal progenitor cells into amacrine or ganglion cells, while dominant-negative studies by the same group yielded fewer amacrine and ganglion cells. No changes in GABAergic cell populations were seen during these experiments by Mo et al. (2004) but a later group (Ding et al., 2009) reported changes in GABAergic populations that mirrored changes in glycinergic populations when Barhl2 levels were experimentally modulated. Atoh7 and Pou4f2-null retina experiments caused down-regulation of Barlh2, suggesting these two factors act upstream of Barlh2 (Ding et al., 2009). BumstedO'Brien et al. (2007) demonstrate that another transcription factor, Meis2, may also be involved in glycinergic specification of mouse and human amacrine cells; cells that adopt a glycinergic fate repress Meis2 while GABAergic cells maintain high Meis2 levels, a result which suggests that Meis2 may be a repressor of glycinergic fates.

Over the past decade an increasing body of evidence has accumulated suggesting that neurotransmitter specification may be influenced by activity based mechanisms and environmental factors. It has been suggested that $\mathrm{Ca}^{+2}$ transients may influence the adoption of a neurotransmitter phenotype (reviewed in Spitzer, 2006). Certain patterns of $\mathrm{Ca}^{+2}$ spiking and frequency have been correlated with glutamate, glycine, GABA and acetylcholine neurotransmitter phenotypes. Increased calcium activity is associated with the inhibitory neurotransmitters, while high activity is associated with excitatory. Glycine receptors are found on embryonic Xenopus laevis muscle cells, but expression decreases during the course of normal development. If calcium transients are experimentally altered so as to increase the prevalence of glycinergic neurons, glycinergic currents can be detected on muscle cells (Borodinsky and Spitzer, 2006). There is even some evidence that calcium activity can override some other genetic differentiation signals, as HNK-1 or lim-3 positive cells could be induced to adopt the GABAergic or glycinergic phenotype by experimental inhibition of calcium transients (Spitzer et al., 2004).

\section{THE ROLE OF NONSYNAPTIC GLYCINE DURING DEVELOPMENT}

GlyR subunits $\alpha 2$ and $\beta$ are expressed very early in the developing rat cerebral cortex (E14-P5) (Malosio et al., 1991b). While glycine levels in the cerebral cortex at this time are thought to be too low to allow normal neurotransmission (van den Pol and Gorcs, 1988; Zafra et al., 1995), the amino-sulfonic acid taurine is highly expressed and was hypothesized to act as a ligand for the receptor (Smith et al., 1992). Flint et al. (1998) found evidence supporting the hypothesis that taurine functions as a ligand for GlyR via nonsynaptic signaling in the early neocortex. Indeed, kittens deprived of prenatal taurine develop smaller brains that fail to differentiate normally (Palackal et al., 1986). Since 1998 evidence for nonsynaptic taurine-GlyR signaling has been found in the rat auditory cortex, hippocampus and dopaminergic neurons of the ventral tegmentum and most recently in the spinal cord (Mori et al., 2002; Wang et al., 2005; Scain et al., 2010). Mori et al. (2002) observed that pressure application of glycine onto hippocampal CA3 pyramidal cells exposed to antagonists for ionotropic 
glutatmate and $\mathrm{GABA}_{\mathrm{B}}$ caused currents. These responses were associated with increased chloride conductance and could be halted by treatment with the glycine receptor antagonist strychnine. Together these results suggest the presence of functional GlyR in the early hippocampus, yet no evidence was found connecting these strychnine-sensitive chloride currents to synaptic stimulation. Mori et al. (2002) also found that the application of the $\beta$-alanine and taurine uptake inhibitor guanidinoethanesulfonic acid indicated that the modulation of these transporters could regulate tonic GlyR activation. Studies of rats aged 1-13 days found more evidence of nonsynaptic glycine signaling in dopaminergic neurons of ventral tegmentum acute brain slices. Currents were observed in current clamped neurons after the application of $0.01-0.03 \mathrm{mM}$ taurine via interaction with non-synaptic GlyRs (Wang et al., 2005), providing additional support for non-synaptic or "preneural" glycinergic transmission. Outside of the brain, nonsynaptic glycine signaling was recently observed in the radial cells of the spinal cord using an outside-out sniffer technique measuring glycine release between E12.5 and E14. This signaling is attributed to glycine itself and not taurine, which is was not observed in immunostained radial cells at this stage of development. Radial cells were also observed to release glycine upon mechanical stimulation and to produce spontaneous rhythmic behavior in nearby immature neurons. To fully prove the existence of a nonsynaptic glycine signaling system endogenous glycine release must be demonstrated in addition to expression of functional GlyR (Scain et al., 2010).It must also be noted that the studies in support of nonsynaptic glycine signaling are limited due to the pharmacological tools used in the studies. Guanidinoethanesulfonic acid, for example, blocks taurine transporter and is a $\mathrm{GABA}_{\mathrm{A}}$ receptor agonist, while sarcosine blocks GlyT and serves as a co-agonist for NMDA receptor and a full agonist for GlyR (Mangin et al., 2002; Zhang et al., 2009a,b). While the role of non-synaptic glycine signaling remains somewhat unclear, if not controversial, there is compelling evidence demonstrating a determinative role for glycinergic signaling during the early stages of synapse and network formation in the spinal cord, brain, and retina.

\section{THE ROLE OF GLYCINE IN NEURAL DEVELOPMENT THE ROLE OF GLYCINE IN SPINAL CORD DEVELOPMENT}

Glycinergic neurotransmission develops first in the spinal cord. Immature neural circuits of the developing spinal cord can spontaneously generate synchronous rhythmic activity patterns that can be classified as central pattern generators (CPGs) if they include multiple processes that act in an ascending and descending manor that successfully returns to a starting point. CPGs are often associated with rhythmic respiration, swallowing, and early locomotion. These spontaneous bursts can be caused by several neurotransmitters, including the normally inhibitory neurotransmitters GABA and glycine. Experiments using the GlyR antagonist strychnine and L-type $\mathrm{Ca}^{+2}$ blockers on spinal neurons suggest that GlyR activation leads to $\mathrm{Ca}^{+2}$ transients that in turn cause accumulation of the anchoring protein Gephyrin and GlyR. Taken together these results support an activity-driven model for synapse formation (Kirsch and Betz, 1998). Young neurons, which do not yet express the $\mathrm{K}+$ / $\mathrm{Cl}$ - co-transporter KCC2, typically have higher internal chloride ion concentrations when compared to the exterior of the cell, so activation of glycine dependent chloride channels results in depolarization instead of hyper-polarization observed in mature neurons (Reichling et al., 1994; Rivera et al., 1999). In some instances GABA and glycine have been shown to be active at the same synapse (Singer and Berger, 2000; Gao et al., 2001).

GlyR has been implicated in regulating interneuron differentiation in the zebrafish spinal cord. Targeted knockdown of the GlyR embryonic subunit $\alpha 2$ resulted in disruption of rhythm-generating networks and an increase in the number of mitotic cells (McDearmid et al., 2006). Studies using GlyR and GABA A receptor antagonists found that GABAergic and glycinergic synapses each have unique roles in modulating locomotion rhythms. Glycine functions to stabilize patterns of alternating rhythms (Hinckley et al., 2005). Although GABA may have a stronger role in the maturation of locomotor circuitry, glycine becomes the main neurotransmitter responsible for mediating reciprocal coupling between mature antagonistic motor centers in the mouse spinal cord (Sibilla and Ballerini, 2008).

Glycine transporters have also been shown to play an important role in CPG development. Hanson and Landmesser (2004) used strychnine to block or slow spontaneous rhythmic firing produced by glycinergic neurons. They showed that spontaneous bursting activity is necessary for motoneurons to make their first dorsal/ventral pathfinding decisions, perhaps due to differential expression of EphA4 and polysialic acid on NCAM. Later the same group (Hanson and Landmesser, 2006) used sarcosine to block GlyT1 activity and modulate spontaneous rhythmic firing. These investigators found that altering burst frequency disrupted dorsal/ ventral and anterior/posterior pathfinding decisions of lumbosacral motoneurons. Mutant motor phenotypes such as mutant EphA4 and ephrinB3 mice are also being utilized to shed light on normal neural development in the spinal cord. Addition of sarcosine returned the mutant synchronous activation pattern back to normal alteration, thus indicating that the balance between excitation and inhibition over the midline was shifted toward excitation in mutants (Kullander et al., 2001, 2003).

One of the most therapeutically interesting aspects of glycine neurotransmission in the spinal cord is its role in the development of nociception. Proper formation of pain perception pathways requires $\mathrm{GABA}_{\mathrm{A}}$ receptors and GlyRs in the dorsal horn. It has been shown that reducing GlyR synaptic inhibition can lead to hypersensitivity to pain (Ahmadi et al., 2002; Coull et al., 2003). Harvey et al. (2004) have shown that GlyR $\alpha 3$, which is expressed in the superficial laminae of the mouse dorsal horn, plays a pivotal role in inflammatory pain sensitization by demonstrating that prostaglandin $\mathrm{E}_{2}$-induced synaptic inhibition is completely abolished in GlyR $\alpha 3-/-$ mice. Although most inhibitory synapses are GABAergic in rodent neonates, the balance shifts in favor of glycinergic synapses during maturation (Baccei and Fitzgerald, 2004). GlyR and the glycine transporters GlyT1 and GlyT2 are currently being investigated as pharmacological targets for the treatment of pain disorders (reviewed in Dohi et al., 2009).

\section{THE ROLE OF GLYCINE IN BRAIN DEVELOPMENT}

The role of glycinergic neurotransmission in the brain presents a more complex story that is far from fully understood. Although certain areas have seen heavy research, such as the lateral superior olive, many have yet to be pursued in depth. Development of 
respiratory neural circuits has long been known to involve inhibitory neurotransmission and glycine in particular. Although it is unclear if glycine is absolutely required for the generation of basic breathing rhythms in neonate rodents, there is strong evidence that glycine plays a role in modulating and patterning. Respiratory rhythms are not abolished by application of glycine or GABA antagonists or alteration of extracellular chloride ion concentrations (Onimaru et al., 1990). Experimentally introduced exogenous glycine can, however, augment the frequency and amplitude of respiratory rhythms. Conversely, mice without functional GlyT1 are unable to breathe properly at birth and die within the first day. The strong connection between glial glycine and respiration may be mediated via suppression of NMDA receptor function, although experimental evidence in support of this hypothesis has yet to be gathered (Gomeza et al., 2004). The investigation of the exact role of glycinergic neurons in the development of this system has been confusing and contradictory. Some investigators have reported that glycine causes hyperpolarization and depression of respiration in the neonatal spinal cord and brainstem, which is surprising given the lack of KCC2 channel expression before E19 in rats to form the $[\mathrm{K}+]$ necessary to drive such activity (Brockhaus and Ballanyi, 1998; Ren and Greer, 2006). Others have found that glycine causes depolarization of neurons involved in respiration in the developing medulla (Ritter and Zhang, 2000). Ren and Greer (2006) have proposed that these discrepancies may be due to differences in $\left[\mathrm{K}^{+}\right]_{0}$ used in each of these studies.

The developing hippocampus appears to utilize excitatory glycinergic signaling for proper neural network formation. The adult inhibitory neurotransmitters GABA and glycine have been implicated in giant depolarizing potentials (GDPs) in the hippocampus in studies on rats, rabbits and rhesus macaques. GDPs are associated with changes in intracellular $\mathrm{Ca}^{+2}$ transients, especially the CA3 region. Observation of GDPs in hippocampal slices from these species suggests that glycine may play an important role in hippocampal network formation across mammal lineages (Prida et al., 1998; reviewed in Ben-Ari, 2001).

The central auditory system is one of the best characterized examples of glycinergic neurotransmission in the developing mammalian brain. The lateral superior olive (LSO) is one of the first stations in the ascending auditory pathway. The LSO receives excitatory inputs from the cochlear nucleus and inhibitory inputs from the medial nucleus of the trapezoid body in the adult. From fetal stages through postnatal day 7 in gerbils and rats glycinergic transmission results in excitatory postsynaptic potentials. This period of dual excitatory input occurs during an important stage of neuronal growth and strengthening of dendritic arbors (Sanes and Friauf, 2000). A growing body of evidence is connecting this period of glycine induced depolarization with LSO network maturation via modulating intracellular $\mathrm{Ca}^{+2}$ concentrations (Malenka and Nicoll, 1993; Sanes and Friauf, 2000). Kandler et al. (2002) have demonstrated that glycinergic inputs of the LSO at this stage can induce increased $\mathrm{Ca}^{+2}$ concentrations and action potentials using calcium imaging techniques. More recently Kullmann and Kandler (2008) showed that subthreshold synaptic responses result in local changes in $\mathrm{Ca}^{+2}$ concentration, while suprathreshold responses elicit global $\mathrm{Ca}^{+2}$ modulations throughout the dendrites of the postsynaptic cell. Seven days after birth glycinergic neurons adopt adult inhibitory neurotransmission. This new stage again mirrors a change in the maturation of LSO neural networks; synaptic pruning. It is hypothesized that the change in the survivability of dendrite arbors is connected to the change in glycinergic transmission.

The theme of postsynaptic potential switching during neural circuit modeling is observed in numerous instances over the course of development. Glycinergic neurotransmission has been shown to influence neural maturation via similar mechanisms in the respiratory brainstem nuclei, hippocampus, and the LSO of the auditory system (Ben-Ari, 2001). It is unclear how many other neural pathways glycinergic signaling may influence (Young-Pearse et al., 2006).

\section{THE ROLE OF GLYCINE IN RETINAL DEVELOPMENT}

Glycinergic transmission and GlyR mediated taurine signaling have been shown to play important roles in embryonic and early postnatal retinal development. GlyR mediated taurine signaling has been implicated in directing the proliferation of rod photoreceptor cells, while glycinergic transmission has been shown to be important to light-dependent maturation of retinal ganglion cells and bipolar cells. Studies in chicks and rats have given varied results, indicating that the glycine's function in retinal development may not be well conserved between taxa (Berki et al., 1995; Sassoe-Pognetto and Wassle, 1997).

Overexpression of GlyR subunit $\alpha 2$ leads to the development of double the percentage of rod photoreceptors at the expense of Muller glial cells. Mutation studies of the gene for the GlyR $\beta$ subunit had little effect on the outer retina, photoreceptors or bipolar cells. These results indicate the importance of the $\alpha 2$ subunit in taurine signaling. Inhibition of taurine uptake by guanidinoethylsulfate and introduction of exogenous taurine both resulted in an increased percentage of photoreceptor cells in the mature retina. It is unclear exactly how GlyR mediated taurine signaling directs rod photoreceptor cell differentiation. Since no increased cell death is observed in GlyR $\alpha 2$ over expression experiments, it is thought that GlyR mediated taurine signaling causes cells to exit the mitotic cycle, only to later adopt the rod photoreceptor phenotype. Taurine's ability to directly induce rod photoreceptor cells regardless of mitotic state via GlyR activation remains untested. In addition to taurine signaling, it has been shown that rod photoreceptor cell differentiation requires a combination of GABA and glycine. The pharmacology of this interaction is yet to be determined (Sassoe-Pognetto and Wassle, 1997; Young and Cepko, 2004).

The role of glycinergic transmission in the development of ganglion cells has been investigated using a line of mutant mice known as spastic. These mice possess an insertion of the transposable element (LINE1) in the 5 th intron for the $\beta$ subunit gene of GlyR, causing aberrant mRNA splicing (Kingsmore et al., 1994; Mulhardt et al., 1994). Although mutations in this gene appeared to have few effects on photoreceptors or bipolar cells, the $\beta$ subunit appears to be important in the development of retinal ganglion cells. Xu and Tian (2008) found that retinal ganglion cells failed to form properly in the center through the sublamina $a$ of the inner plexiform layer of the retina. These investigators also observed the same pattern of mis-expression in normal mice raised in light-deprived conditions. 
Together these results suggest that the mechanism connecting optic stimulation to the maturation of retinal ganglion cell connectivity is mediated via GlyR synaptic transmission.

\section{CONCLUSIONS AND FUTURE DIRECTIONS}

As is apparent from the literature cited in the previous sections, the amino acid glycine, which serves as an essential inhibitory neurotransmitter in the adult nervous system, also plays a myriad of important roles in neural development. While significant progress has been made in elucidating the various roles of glycinergic signaling during embryogenesis as well as the mechanisms by which neurons adopt this important neurotransmitter phenotype, recent findings have raised new questions and opened fresh avenues of research.

For example, one area that is particularly ripe for future study and potentially very informative for the field of glycinergic neurotransmission is an integrative "evo-devo" approach that combines expression data with analyses of upstream regulatory regions from an array of different species. The detailed analyses of the developmental expression patterns on the individual glycinergic phenotype markers have provided much of the necessary groundwork for future comparative studies. Nevertheless, to close the gaps in our knowledge, a systematic and comparative analysis of glycine IR and GlyT2, VIAAT, and the GlyR on both the mRNA and protein level in each of the major model organisms would be informative. Additionally, to date, there has been little developmental analysis of glycinergic markers in non-model systems, an endeavor that would provide increased comparative richness. However, for an integrated understanding, expression studies from a variety of species should be combined with functional analyses of the upstream regulatory regions that govern the expression of the various domains of each of the glycinergic markers. Currently there are virtually no detailed analyses of the regulatory regions controlling the expression patterns of any of the glycinergic marker genes. The availability of sequenced genomes from a variety of species and programs such as PipMaker allows investigators to conduct powerful in silico analysis to identify regions of conservation in non-coding regions among divergent species, regions that may serve as important evolutionarily conserved regulatory control regions (Elnitski et al., 2003). While not a substitute for in vivo transgenic analysis which demonstrates that a given stretch of DNA drives a specific realm of expression, in silico analysis provides a means to conduct global comparative genomic analyses and can potentially identify important conserved regulatory regions, even hundreds of kilobases up- or downstream of the coding region. For example, $5 \mathrm{~kb}$ of DNA upstream of the X. laevis GlyT2 gene was compared to upstream sequences from $X$. tropicalis, zebrafish, mouse and human in silico using PipMaker software. Three conserved non-coding (CNC) regions were observed $4.7 \mathrm{~kb}, 2 \mathrm{~kb}$, and 200 bp upstream of the start site (unpublished data), suggesting a possible regulatory role. Understanding the regulation of "terminal differentiation" genes such as GlyT2 or VIAAT is a particularly interesting problem given that many genes associated with the differentiated phenotype display profoundly similar expression patterns across species, yet do not share significant sequence similarity in their regulatory regions. Although exact expression for glycinergic markers obviously differs among these organisms, the general pattern of expression timing and location is maintained between these groups. Further analysis of control regions of the glycinergic genes may shed light on this important issue in transcriptional regulation as well as on the evolution of glycinergic signaling. Recent work has also questioned the previous view that glycinergic signaling is unique to the vertebrate lineage. Cloning and sequence analysis accompanied by careful expression data on both the mRNA and protein level from organisms representing a variety of different phyla should resolve this question and also address the broader evolutionary issue.

While analysis of regulatory regions has the potential to identify novel factors not yet known to be involved in glycinergic specification, recent work has already identified a number of factors known to be involved in this process. Additional analysis along the lines of Batista and Lewis (2008), Huang et al. (2008), and Joshi et al. (2009) on how these individual factors interact in a network will be essential; the use of chip and high throughput sequencing technologies to conduct more global analyses of gene expression during glycincergic specification and following the inactivation of putative glycinergic regulatory genes will provide a more complete picture of the gene networks involved. However, these approaches must still be complemented by gene expression analysis at the single cell level, the level at which specification is actually occurring. Indeed, one of the difficulties of glycinergic phenotype specification is that many, if not all, of the identified factors also serve as GABAergic specification factors. This intriguing feature may also present a valuable clue to the underlying mechanism of determination, namely that cells initially co-express GABAergic and glycinergic determination factors as well as differentiation markers prior to selecting one or the other system, a hypothesis supported by co-expression data (Aubrey et al., 2007) and electophysiological data (Muller et al., 2006, 2008). Interestingly, the developmental kinetics of glycine closely mirrors GABA in most of the phyla in which comparative expression studies have been conducted, with glycincergic neurons often, but not always, developing slightly later. Additional colocalization studies of glycinergic and GABAergic phenotype markers (as well as other neurotransmitter markers) throughout development on the single cell level are clearly indicated. These studies would be particularly useful if they are complemented with electrophysiological analyses to determine if and when the gene expression correlates with functional synaptic signaling.

The relative roles of "hard-wired" transcriptional regulatory control versus activity-dependent mechanisms remain an important issue in glycinergic specification and in neurotransmitter phenotype determination generally. Recent work has demonstrated that neurotransmitter specification has an activity-dependent component in which high levels of activity as evidenced by calcium spiking is associated with the development of inhibitory phenotypes and lower levels correlated with the formation of excitatory phenotypes. Whether activity-dependent mechanisms or hard-wired molecular switches are responsible for glycincergic determination requires additional research.

Equally important is the function of glycinergic signaling during development. Clearly the presynaptic role remains controversial and understudied. Elucidation will require careful and sensitive expression assays for each of the components to ensure that the "machinery" is present, followed by rigorous functional 
perturbation experiments in multiple species. A recent study showing that inhibitory and excitatory phenotypes may be mediated by presynaptic GABA lend support to a possible presynaptic role for glycine (Root et al., 2008), however identification of the molecular mechanisms, that is, the presence of a receptor, is essential. While the presynaptic role remains problematic, the role of glycine and glycinergic neurons in circuit and network development has assumed a new importance. Continued functional studies employing conditional knockouts to identify new or early roles will continue to be informative. An integrated approach using detailed gene expression and electrophysiological methodologies as employing the tools of comparative genomics and "evo-devo" analysis combined with functional assays including novel gene swapping experiments (along the lines of those conducted by Aubrey et al. (2007)) will provide an encompassing picture of how this important phenotype is specified and its numerous roles in the development of the nervous systems.

\section{ACKNOWLEDGMENTS}

We thank Dr. Eric Bradley for useful suggestions on the manuscript. Support was provided by a grant from the Howard Hughes Medical Institute Undergraduate Science Education Program to the College of William and Mary and from the NIH (to MSS, R15NS067566).

\section{REFERENCES}

Abalo, X. M., Villar-Cervino, V., VillarCheda, B., Anadon, R., and Rodicio, M. C. (2008). Neurochemical differentiation of horizontal and amacrine cells during transformation of the sea lamprey retina. J. Chem. Neuroanat. 35, 225-232.

Adams, R. H., Sato, K., Shimada, S., Tohyama, M., Puschel, A. W., and Betz, H. (1995). Gene structure and glial expression of the glycine transporter GlyT1 in embryonic and adult rodents. J. Neurosci. 15, 2524-2532.

Ahmadi, S., Lippross, S., Neuhuber, W. L., and Zeilhofer, H. U. (2002). PGE2 selectively blocks inhibitory glycinergic neurotransmission onto rat superficial dorsal horn neurons. Nature 5, 34-40.

Allain, A., Bairi, A., Meyrand, P., and Branchereau, P. (2006). Expression of the glycinergic system during the course of embryonic development in the mouse spinal cord and its co-localization with GABA immunoreactivity. J. Comp. Neurol. 496, 832-846.

Aubrey, K. R., Rossi, F. M., Ruivo, R., Alboni, S., Bellenchi, G. C., Goff, A. L., Gasnier, B., and Supplisson, S. (2007). The transporters GlyT2 and VIAAT cooperate to determine the vesicular glycinergic phenotype. J. Neurosci. 27, 6273-6281.

Baccei, M. L., and Fitzgerald, M. (2004). Development of GABAergic and glycinergic transmission in the neonatal rat dorsal horn. J. Neurosci. 24, 4749-4757.

Bargmann, C. (1998). Neurobiology of the Caenorhabditis elegans genome. Science 282, 2020-2033.

Batista, M. F., and Lewis, K. E. (2008). Pax $2 / 8$ act redundantly to specify glycinergic and GABAergic fates of multiple spinal interneurons. Dev. Biol. 232, 88-97.

Becker, C. M., Hoch, W., and Betz, H. (1988). Glycine receptor heterogeneity in rat spinal cord during postnatal development. EMBO J. 7, 3717-3726.
Ben-Ari, Y. (2001). Developing networks play a similar melody. Trends Neurosci. 24, 353-360.

Berki, A. C., O’Donovan, M. J., and Antal, M. (1995). Developmental expression of glycine immunoreactivity and its colocalization with GABA in the embryonic chick lumbosacral spinal cord. J. Comp. Neurol. 362, 583-596.

Betz, H., and Laube, B. (2006). Glycine receptors: recent insights into their structural organization and functional diversity. J. Neurochem. 97, 1600-1610.

Borodinsky, L. N., and Spitzer, N. C. (2006). Activity-dependent neurotransmitter-receptor matching at the neuromuscular junction. PNAS 104, 335-340.

Brockhaus, J., and Ballanyi, K. (1998). Synaptic inhibition in the isolated respiratory network of neonatal rats. Eur. J. Neurosci. 10, 3823-3839.

Bumsted-O’Brien, K. M., Hendrickson, A., Haverkamp, S., Ashery-Paden, R., and Schulte, D. (2007). Expression of the homeodomain transcription factor meis 2 in the embryonic and postnatal retina. J. Comp. Neurol. 505, 58-72.

Burzomato, V., Groot-Kormelink, P. J., Sivilotti, L. G., and Beato, M. (2003). Stoichiometry of recombinant heteromeric glycine receptors revealed by a pore-lining region point mutation. Recept. Channels 9, 353-361.

Coull, J. A., Boudreau, D., Bachand, K., Prescott, S. A., Nault, F., Sik, A., De Konink, P., and De Konink, Y. (2003). Trans-synaptic shift in anion gradient in spinal lamina I neurons as a mechanism of neuropathic pain. Nature 424, 938-942.

Cui, W. W., Low, S. E., Hirata, H., SaintAmant, L., Geisler, R., Hume, R. I., and Kuwada, J. Y. (2005). The Zebrafish shocked gene encodes a glycine transporter and is essential for the function of early neural circuits in the CNS. $J$. Neurosci. 25, 6610-6620.

Ding, Q., Chen, H., Xie, X., Libby, R. T., Tian, N., and Gan, L. (2009). Barhl2 differentially regulates the development of retinal amacrine and ganglion neurons. J. Neurosci. 29, 3992-4003.

Dohi, T., Morita, K., Kitayama, T., Motoyama, N., and Morioka, N. (2009). Glycine transporter inhibitors as a novel drug discovery strategy for neuropathic pain. Pharmacol. Ther. 123, 54-79.

Ebihara, S., Yamamoto, T., Obata, K., and Yanagawa, Y. (2004). Gene structure and alternative splicing of the mouse glycine transporter type- 2 . Biochem. Biophys. Res. Commun. 317, 857-864.

Elnitski, L., Riemer, C., Schwartz, S., Hardison, R., and Miller, W. (2003). PipMaker: a world wide web server for genomic sequence alignments. Curr. Protoc. Bioinformatics Chapter 10, Unit 10.2.

Eulenburg, V., Becker, K., Gomeza, J., Schmitt, B., Becker, CM., and Betz, H. (2006). Mutations within the human GlyT2 (SLC6A5) gene associated with hyperekplexia. Biochem. Biophy. Res. Commun. 348, 400-405.

Feng, G., Tintrup, H., Kirsch, J., Nichol, M. C., Kuse, J., Betz, H., and Sanes, J. R. (1998). Dual requirement for gephyrin in glycine receptor clustering and molybdoenzyme activity. Science 282, 1321-1324.

Fletcher, E. L., and Kalloniatis, M. (1997). Localisation of amino acid neurotransmitters during postnatal development of the rat retina. J. Comp. Neurol. 380, 449-471.

Flint, A. C., Liu, X., and Kriegstein, A. R. (1998). Nonsynaptic glycine receptor activation during early neocortical development. Neuron 20, 43-53.

Friauf, E., Aragon, C., Lohrke, S., Westenfelder, B., and Zafra, F. (1999). Developmental expression of the glycine transporter GlyT2 in the auditory system of rats suggests involvement in synapse maturation. J. Comp. Neurol. 412, 17-37.

Fujiyama, T., Yamada, M., Terao, M., Terashima, T., Hioki, H., Inoue, Y. U., Inoue, T., Masuyama, N., Obata, K., Yanagawa, Y., Kawaguchi, Y.,
Nabeshima, Y., and Hoshino, M. (2009). Inhibitory and excitatory subtypes of cochlear nucleus neurons are defined by distinct bHLH transcription factors, Ptfla and Atoh1. Development 136, 2049-2058.

Gao,B.,Stricker, C., and Zisking-Conhaim, L. (2001). Transition from GABAergic to glycinergic synaptic transmission in newly formed spinal networks. $J$. Neurophysiol. 86, 4920502.

Gomeza, J., Hulsmann, S., Ohno, K., Eulenburg, V., Szoke, K., Richter, D., and Betz, H. (2004). Inactivation of the glycine transporter 1 gene discloses vital role of glial glycine uptake in glycinergic inhibition. Neuron 40 , 785-796.

Grenningloh, G., Schmieden, V., Schofield, P. R., Seeburg, P. H., Siddique, T., Mohandas, T. K., Becker, C. M., and Betz, H. (1990). Alpha subunit variants of the human glycine receptor: primary structures, functional expression and chromosomal localization of the corresponding genes. EMBO 9, 771-776.

Grimmelikhuijzen, C. J. P., Williamson, M., and Hansen, G. N. (2002). Neuropeptides in cnidarians. Can. J. Zool. 80, 1690-1702.

Grudzinska, J., Schemm, R., Haeger, S., Nicke, A., Schmalzing, G., Betz, H., and Laube, B. (2005). The beta subunit determines the ligand binding properties of synaptic glycine receptors. Neuron 45, 727-739.

Grunert, U. (2000). Distribution of GABA and glycine receptors on bipolar and ganglion cells in the mammalian retina. Microsc. Res. Tech. 50, 130-140.

Gurrola-Diaz, C., Lacroix, J., Dihlmann, S., Becker, C., and von Knebel Doeberitz, M. (2003). Reduced expression of the neuron restrictive silencer factor permits transcription of glycine receptor $\alpha 1$ subunit in small-cell lung cancer cells. Oncogene 22, 5636-5645.

Hanson, G. M., and Landmesser, L. T. (2004). Normal patterns of spontaneous activity are required for correct 
motor axon guidance. Neuron 43 , 687-701.

Hanson, G.M., and Landmesser,L.T.(2006). Increasing the frequency of spontaneous rhythmic activity disrupts pool-specific axon fasciculation and pathfinding of embryonic spinal motoneurons. $J$. Neurosci. 26, 12769-12780.

Harvey, R. J., Depner, U. B., Wassle, H., Ahmadi, S., Heindl, C., Reinold, H., Smart, T.G., Harvey, K., Schutz, B.,AboSalem, O. M., Zimmer, A., Poisbeau, P., Wlzl, H., Wolfer, D. P., Betz, H., Zeilhofer, H. U., and Muller, U. (2004). GlyR $\alpha 3$ : an essential target for spinal PGE2-mediated inflammatory pain sensitization. Science 304, 884-887.

Hering, H., and Kröger, S. (1996). Formation of synaptic specializations in the inner plexiform layer of the developing chick retina. J. Comp. Neurol. 3, 393-405.

Higashijima, S., Mandel, G., and Fetcho, J. R. (2004). GABAergic neurons in embryonic and larval zebrafish. $J$. Comp. Neurobiol. 480, 1-18.

Hinckley, C., Seebach, B., and ZiskindConhaim, L. (2005). Distinct roles of glycinergic and GABAergic inhibition in coordinating locomotor-like rhythms in the neonatal mouse spinal cord. Neuroscience 131, 745-758.

Hirata, H., Saint-Amant, L., Downes, G. B., Cui, W. W., Zhou, W., Granato, M., and Kuwada, J. Y. (2005). Zebrafish bandoneon mutants display behavioral defects due to a mutation in the glycine receptor $\beta$-subunit. PNAS 102, 8345-8350.

Huang, M., Huang, T., Xiang, Y., Xie, Z., Chen, Y., Yan, R., Xu, J., and Cheng, L. (2008). Ptf1a, Lbx1 and Pax2 coordinate glycinergic and peptidergic transmitter phenotypes in dorsal spinal inhibitory neurons. Dev. Biol. 322, 394-405.

Ichinohe, A., Kure, S., Mikawa, S., Ueki, T., Kojima, K., Fujiwara, K., Linuma, K., Matsubara, Y., and Sato, K. (2004). Glycine cleavage system in neurogenic regions. Eur. J. Neurosci. 19, 2365-2370.

Imboden, M., Devignot, V., Korn, H., and Goblet, C. (2001). Regional distribution of glycine receptor messenger RNA in the central nervous system of Zebrafish. Neuroscience 103, 811-830.

Johnson, J., Tian, N., Caywood, M. S., Reimer, R. J., Edwards, R. H., and Copenhagen, D. R. (2003). Vesicular neurotransmitter transporter expression in developing postnatal rodent retina: GABA precedes glutamate. $J$. Neurosci. 23, 518-529.

Joshi, K., Lee, S., Lee, E., Lee, J. W., and Lee, S. (2009). LMO4 controls the balance between excitatory and inhibitory spinal V2 interneurons. Neuron $61,839-851$.
Jursky, F., and Nelson, N. (1996). Developmental expression of the glycine transporters GlyT1 and GlyT2 in the mouse brain. J. Neurochem. 67, 336-344.

Kandler, K., Ene, A., and Kullmann, P. H. M. (2002). Glycinergic and GABAergic calcium responses in the developing lateral superior olive. Eur. J. Neurosci. 15, 1093-1104.

Kannenberg, K., Sieghart, W., and Reuter, H. (1999). Clusters of GABAA receptors on cultured hippocampal cells correlate only partially with functional synapses. Eur. J. Neurosic. 11, 1256-1264.

Kehoe, J., Buldakova, S., Acher, F., Dent, J., Bregestovski, P., and Bradley, J. (2009). Aplysia cys-loop glutamate-gated chloride channels reveal convergent evolution of ligand specificity. J. Mol. Evol. 69, 125-141.

Kingsmore, S. F., Giros, B., Suh, D., Bieniarz, M., Caron, M. G., and Seldin, M. F. (1994). Glycine receptor $\beta$-subunit gene mutation in spastic mouse associated with LINE-1 element insertion. Nat. Genet. 7, 136-142.

Kirsch, J. (2006). Glycinergic transmission. Cell Tissue Res. 326, 535-540.

Kirsch, J., and Betz, H. (1998). Glycinereceptor activation is required for receptor clustering in spinal neurons. Nature 392, 717-720.

Kneussel, M., Hermann, A., Kirsch, J., and Betz, H. (1999). Hydrophobic interactions mediate binding of the glycine receptor $\beta$-subunit to gephyrin. J. Neurochem. 72, 1323-1326.

Kuhse, J., Kuryatov,A., Maulet, Y., Malosio, M. L., Schmieden, V., and Betz, H. (1991). Alternative splicing generates two isoforms of the $\alpha 2$ subunit of the inhibitory glycine receptor. FEBS. 283, 73-77.

Kuhse, J., Laube, B., Magalei, D., and Betz, H. (1993). Assembly of the inhibitory glycine receptor: identification of amino acid sequence motifs governing subunit stoichiometry. Neuron 11 , 1049-1056.

Kuhse, J., Schmieden, V., and Betz, H. (1990). A single amino acid exchange alters the pharmacology of neonatal rat glycine receptor subunit. Neuron 5, 867-873.

Kullander, K., Butt, S. J. B., Lebret, J. M., Lundfald, L., Restrepo, C.E., Rydstrom, A., Klein, R., and Kiehn, O. (2003). Role of EphA4 an dEphrinB3 in local neuronal circuits that control walking. Science 299, 1889-1892.

Kullander, K., Croll, S. D., and Zimmer, M. (2001). Ephrin-B3 is the midline barrier that prevents corticospinal tract axons from recrossing, allowing for unilateral motor control. Genes Dev. $15,877-888$.
Kullmann,P.H.M., and Kandler,K. (2008). Dendritic $\mathrm{Ca}+2$ responses in neonatal lateral superior olive neurons elicited by glycinergic/GABAergic synapses and action potentials. Neuroscience $154,338-345$.

Legendre, P. (2001). The glycinergic inhibitory synapse. Cell. Mol. Life Sci. 58, 760-793.

Levi, S., Logan, S. M., Tovar, K. R., and Craig, A. M. (2004). Gephyrin is critical for glycine receptor clustering but not for the formation of functional GABAergic synapses in hippocampal neurons. J. Neurosci. 24, 207-217.

Malenka, R. C., and Nicoll, R. A. (1993). NMDA-receptor-dependent synaptic plasticity: multiple forms and mechanisms. Trends Neurosci. 16, 521-527.

Malosio, M. L., Grenningloh, G., Kuhse, J., Schmieden, V., Schmitt, B., Prior, P., and Betz, H. (1991a). Alternative splicing generates two variants of the alpha 1 subunit of the inhibitory glycine receptor. J. Biol. Chem. 266, 2048-2053.

Malosio, M.L., Marqueze-Pouey, B., Kuhse, J., and Betz, H. (1991b). Widespread expression of glycine receptor subunit mRNAs in the adult and developing rat brain. EMBO 10, 2401-2409.

Mangin, J. M., Guyon, A., Eugene, D., Paupardin-Tritsch, D., and Legendre, P. (2002). Functional glycine receptor maturation in the absence of glycinergic input in dopaminergic neurons of the rat substantia nigra. J. Physiol. $542,685-697$.

McDearmid, J. R., Liao, M., and Drapeau, P. (2006). Glycine receptors regulate interneuron differentiation during spinal network development. PNAS 103, 9679-9684.

Meier, J., Meunier-Durmort, C., Forest, C., Triller, A., and Vannier, C. (2000). Formation of glycine receptor clusters and their accumulation at synapses. $J$. Cell Sci. 113, 2783-2795.

Mladinic, M., Becchetti, A., Didelon, F., Bradbury,A., and Cherubini, E. (1999). Low expression of the CIC-2 chloride Channel during postnatal development: a mechanism for the paradoxical depolarizing action of GABA and glycine in the hippocampus. Proc. $R$. Soc. Lond. B 266, 1207-1213.

Mo, Z., Li, S., Yang, X., and Xiang, M. (2004). Role of the Barhl2 homeobox gene in the specification of glycinergic amacrine cells. Development 131 , 1607-1618.

Mori, M., Gahwiler, B. H., and Gerber, U. (2002). B-alanine and taurine as endogenous agonists at glycine receptors in rat hippocampus in vitro. $J$. Physiol. (Lond.) 539, 191-200.

Mulhardt, C., Fischer, M., Gass, P., SinomChazottes, D., Guenet, J., Kuhse, J., Betz, H., and Becker, C. (1994). The spastic mouse: aberrant splicing of gly- cine receptor $\beta$ subunit mRNA caused by intronic insertion of L1 element. Neuron 13, 1002-1015.

Muller, E., Corronc, H. L., Scain, A. L. Triller, A., and Legendre, P. (2008). Despite GABAergic neurotransmission, GABAergic innervations does not compensate for the defect in glycine receptor postsynaptic aggregation in spastic mice. Eur. J. Neurosci. 27, 2529-2541.

Muller, E., Corronc, H. L., Triller, A., and Legendre,P. (2006). Developmental dissociation of presynaptic inhibitory neurotransmitter and postsynaptic receptor clustering in the hypoglossal nucleus. Mol. Cell. Neurosci. 32, 254-273.

Muller,E., Triller,A., and Legendre,P. (2004). Glycine receptors and GABAA receptors $\alpha 1$ and $\gamma 2$ subunits during the development of mouse hypoglossal nucleus. Eur. J. Neurosci. 20, 3286-3300.

Nakhai, H., Saadettin, S., Favor, J., Mendoza-Torres, L., Paulsen, F., Duncker, G. I. W., and Schmid, R. M. (2007). Ptfla is essential for the differentiation of GABAergic and glycinergic amacrine cells and horizontal cells in the mouse retina. Development 134 , 1151-1160.

Neumann, S. B., Seitz, R., Gorzella, A., Heister, A., von Knebel Doeberitz, M., and Becker, C. (2004). Relaxation of glycine receptor and onconeural gene transcription control in NRSF deficient small cell lung cancer cell lines. Mol. Brain Res. 120, 173-181.

Nikolic, Z., Laube, B., Weber, R. G., Lichter, P., Kioschis, P., Poustka, A., Mulhardt, C., and Becker, C. M. (1998). The human glycine receptor subunit $\alpha 3$ gene structure, chromosomal localization and functional characterization of alternative transcripts.J. Biol. Chem. 473, 19708-19714.

Nusser, Z., Sieghart, W., Benke, D., Fritschy, J. M., and Somogy, P. (1996). Differential synaptic localization of two major $\gamma$-aminobutyric acid type A receptor $\alpha$ subunits on hippocampal pyramidal cells. Proc. Natl. Acad. Sci. U. S. A. 93, 11939-11944.

Nusser, Z., Sieghart, W., and Somogy, P. (1998). Segregation of different GABAA receptors to synaptic and extrasynaptic membranes of crebellar granule cells. J. Neurosci. 18, 1693-1703.

Onimaru, H., Arata, A., and Homma, I. (1990). Inhibitory synaptic inputs to the respiratory rhythm generator in the medulla isolated from newborn rats. Pflugers Arch. 417, 425-432.

Palackal, T., Moretz, R., Wisniewski, D. R., and Sturman, J. A. (1986). Abnormal visual cortex development in the kitten associated with maternal dietary taurine deprivation. J. Neurosci. Res. $15,223-239$. 
Pena-Rangel, M. T., Riesgo-Escovar, J. R., Sanchez-Chavez, G., and Salceda, R. (2008). Glycine transporters (glycine transporter I and glycine transporter 2) are expressed in retina. Neuroreport 19, 1295-1299.

Pierobon, P., Minei, R., Porcu, P., Sogliano, C., Tino, A., and Marino, G. (2001). Putative glycine receptors in Hydra: a biochemical and behavioral study. Eur. J. Neurosci. 14, 1659-1666.

Pierobon, P., Tino, A., Minei, R., and Marino, G. (2004). Different roles of GABA and glycine in the modulation of chemosensory responses in Hydra vulgaris (Cnidaria, Hydrozoa). Hydrobiologia 530/531, 59-66.

Pillai, A., Mansouri, A., Behringer, R., Westphal, H., and Goulding, M. (2007). Lhx1 and Lhx5 maintain the inhibitory-neurotransmitter status of interneurons in the dorsal spinal cord. Development 134, 357-366.

Ponce, J., Poyatos, I., Aragon, C., Gimenez, C., and Zafra, F. (1998). Characterization of the 5 ' region of the rat brain glycine transporter Gly $\mathrm{T} 2$ gene: identification of a novel isoform. Neurosci. Lett. 242, 42-28.

Prida, L. M., Bloea, S., and SanchezAndres, J. V. (1998). Origin of the synchronized network activity in the rabbit developing hippocampus. Eur. J. Neurosci. 10, 899-906.

Rao, A., Cha, E. M., and Craig, A. M. (2000). Mismatched appositions of presynaptic and postsynaptic components in isolated hippocampal neurons. J. Neurosci. 20, 8344-8363.

Rees, M. I., Harvey, K., Pearce, B. R., Chung, S. K., Duguid, I.C., Thomas, P., Beatty, S., Graham, G. E., Armstrong, L., Shiang, R., Abbott, K. J., Zuberi, S. M., Stephenson, J. B., Owen, M. J., Tijssen, M. A., van den Maagdenberg, A. M., Smart, T. G., Supplisson, S., and Harvey, R. J. (2006). Mutations in the gene encoding GlyT2 (SLC6A5) define a presynaptic component of human startle disease. Nat. Genet. 38, 801-806.

Reichling, D. B., Kyrozis, A., Wang, J., and MacDermott, A. B. (1994). Mechanisms of GABA and glycine depolarization-induced calcium transients in rat dorsal horn neurons. J. Physiol. (Lond.) 467, 411-421.

Ren, J., and Greer, J. J. (2006). Modulation of respiratory rhythmogenesis by chloride-mediated conductances during the perinatal period. J. Neurosci. 26, 3721-3730.

Ritter, B., and Zhang, W. (2000). Early postnatal maturation of GABAA mediated inhibition in the brainstem respiratory rhythm-generating net- work of the mouse. Eur. J. Neurosci. 12, 2975-2984.

Rivera, C., Voipio, J., Payne, J. A., Ruusuvuori, E., Lahtinen, H., Lamsa, K., Pirvola, U., Saarma, M., and Kaila, K. (1999). The K+/Cl- co-transporter KCC2 renders GABAhyperpolarizing during neuronal maturation. Nature 397, 251-255.

Roberts, A., Dale, N., Ottersen, O. P., and Storm-Mathisen, J. (1988). Development and characterization of Commissural interneurones in the spinal cord of Xenopus laevis embryos revealed by antibodies to glycine. Development 103, 447-461.

Root, C. M., Velazquez-Ulloa, N. A., Monsalve, G. C., and Minakova, Spitzer, N. C. (2008). Embryonically expressed GABA and glutamate drive electrical activity regulating neurotransmitter specification. J. Neurosci. $28,4777-4784$.

Ruggieri, R. D., Pierobon, P., and KassSimon, G. (2004). Pacemaker activity in Hydra is modulated by glycine receptor ligands. Comp. Biochem. Physiol. 138, 193-202.

Sanes, D. H., and Friauf, E. (2000). Development and influence of inhibition in the lateral superior olivary nucleus. Hear. Res. 147(1-2), 46-58.

Sassoe-Pognetto, M., and Wassle, H. (1997). Subcellular localization of glycine receptors, GABAA receptors, and the anchoring protein gephyrin. J. Comp. Neurol. 381, 158-174.

Sawada, M., McAdoo, D. J., Blankenship, J. E., and Price, C. H. (1980). Modulation of arterial muscle contraction in Aplysia by glycine and neuron R14. Brain Res. 207, 486-490.

Sawada, M., McAdoo, D. J., Ichinose, M., and Price, C. H. (1984). Influences of glycine and neuron R14 on contraction of the anterior aorta of Aplysia. Jpn. J. Physiol. 34, 747-767.

Scain, A. L., Corronc, H. L., Allain, A. E., Muller, E., Rigo, J. M., Meyrand, P., Branchereau, P., and Legendre, P. (2010). Glycine release form radial cells modulates the spontaneous activity and its propagation during early spinal cord development. J. Neurosci. 30, 390-403.

Sibilla, S., and Ballerini, L. (2008). GABAergic and glycinergic interneuron expression during spinal cord development: dynamic interplay between inhibition and excitation in the control of ventral network outputs. Neurobiology 89, 46-60.

Singer, J. H., and Berger, A. J. (2000). Development of inhibitory synaptic transmission to motoneurons. Brain Res. Bull. 53, 553-560.
Smith, K. E., Borden, L. A., Wang, C. H., Hartig, P. R., Branchek, T. A., and Weinshank, R. L. (1992). Cloning and expression of a high affinity taurine transporter from rat brain. Mol. Pharmacol. 42, 563-569.

Spitzer, N. C. (2006). Electrical activity in early neuronal development. Nature $444,707-712$.

Spitzer, N.C., Root, C. M., and Borodinsky, L. N. (2004). Orchestrating neuronal differentiation: patterns of $\mathrm{Ca}+2$ spikes specify transmitter choice. Trends Neurosci. 27, 415-421.

Tino, A., Tortiglione, C., Harvey, R. J. Harvey, K., and Pierobon, P. (2005). Inhibitory Ligand-Gated Channels in the Primitive Organism Hydra vulgaris. Genova: Matter, Materials and Devices Meeting. 22-25 June, p. 4.

Todd, A. J., Watt, C., Spike, R. C., and Sieghart, W. (1996). Colocalizatoin of GABA, glycine, and their receptors at synapses in the rat spinal cord. $J$. Neurosci. 16, 974-982.

Ui-Tei, K., Sakuma, M., Watanabe, Y., Miyake, T., and Miyata, Y. (1995). Chemical analysis of neurotransmitter candidates in clonal cell lines from Drosophila central nervous system, II: neuropeptides and amino acids. Neurosci. Lett. 195, 187-190.

van den Pol, A., and Gorcs, T. (1988). Glycine and glycine receptor immunoreactivity in brain and spinal cord. J. Neurosci. 8, 472-492.

Villar-Cervino, V., Barreiro-Iglesias, A. Anadon, R., and Rodicio, M. C. (2009). Development of glycine immunoreactivity in the brain of the sea lamprey: comparison with $\gamma$-aminobutyric acid immunoreactivity. J. Comp. Neurol. $512,747-767$.

Vitanova,L. (2006).Immunocytochemical study of glycine receptors in the retina of the frog Xenopus laevis. Anat. Embryol. 211, 237-245.

Walker, R. J., Brooks, H. L., and HoldenDye, L. (1996). Evolution and overview of classical transmitter molecules and their receptors. Parasitology 113 , 3-33.

Walker, R. J., and Holden-Dye, L. (1991) Evolutionary aspects of transmitter molecules: their receptors and channels. Parasitology 102, 7-29.

Wang, F., Xiao, C., and Hong Ye, J. (2005). Taurine activates excitatory non-synaptic glycine receptors on dopamine neurons in ventral tegmental area of young rats. J. Physiol. (Lond.) 565, 503-516.

Werman, R., Davidoff, R.A., and Aprison, M. H. (1968). Inhibitory action of glycine on spinal neurons in cat. $J$. Neurophysiol. 31, 81-95.

Wester,M.R., Teasley,D.C., Byers, S. L., and Saha, M.S. (2008). Expression patterns of glycine transporters (xGlyT1, xGlyT2, and xVIAAT) in Xenopus laevis during early development. Gene Expr. Patterns 8, 261-270.

Xu, H. P., and Tian, N. (2008). Retinal ganglion cell dendrites undergo a visual activity-dependent redistribution after eye opening.J. Comp. Neurol. 503, 244-259.

Yoshihara, M., Ensminger, A. W., and Littleton, J. T. (2001). Neurobiology and the Drosophila genome. Funct. Integr. Genomics 1, 235-240.

Young, T. L., and Cepko, C. L. (2004). A role for ligand-gated ion channels in rod photoreceptor development. Neuron 41, 867-879.

Young-Pearse, T. L., Ivic, L., Kriegstein, A. R., and Cepko, C. L. (2006). Characterization of mice with targeted deletion of glycine receptor alpha 2 . Mol. Cell. Biol. 26, 5728-5734.

Zafra, F., Aragon, C., Olivares, L., Danbolt, N. C., Gimenez, C., and StormMathisen, J. (1995). Glycine transporters are differentially expressed among CNS cells. J. Neurosci. 15, 3952-3969.

Zeilhofer,H.U., Studler, B., Arabadzisz,D., Schweizer,C.,Ahmadi,S., Layh, B., Bosl, M.R., and Fritschy,J. (2005). Glycinergic neurons expressing enhanced green fluorescent protein in bacterial artificial chromosome transgenic mice.J. Comp. Neurol. 482, 123-141.

Zhang, H. X., Hyrc, K., and Thio, L. L. (2009a). The glycine transport inhibitor sarcosine is an NMDA receptor co-agonist that differs from glycine. $J$. Physiol. (Lond.) 587, 3207-3220.

Zhang, H. X., Lyons-Warren, A., and Thio, L. L. (2009b). The glycine transport inhibitor sarcosine is an inhibitory glycine receptor agonist. Neuropharmacology 57, 551-555.

Conflict of Interest Statement: The authors declare that the research was conducted in the absence of any commercial or financial relationships that could be construed as a potential conflict of interest.

Received: 01 January 2010; paper pending published: 23 January 2010; accepted: 23 March 2010; published online: 22 April 2010.

Citation: Chalphin $A V$ and Saha MS (2010) The specification of glycinergic neurons and the role of glycinergic transmission in development. Front. Mol. Neurosci. 3:11. doi: 10.3389/fnmol.2010.00011

Copyright $\odot 2010$ Chalphinand Saha. This is an open-access article subject to an exclusive license agreement between the authors and the Frontiers Research Foundation, which permits unrestricted use, distribution, and reproduction in any medium, provided the original authors and source are credited. 